\title{
Culto dos monumentos históricos e projeto imperial na década de 1940: Negociando um passado colonial em Maputo e além
}

\author{
Cult of monuments and imperial project in the 1940s: \\ Negotiating a colonial past in Maputo and beyond
}

Lisandra Franco de Mendonça [a], [b] [i], Ricardo Mendonça [c] [i]

[a] Universidade do Minho, Lab2PT - Laboratório de Paisagens, Património e Território, Escola de Arquitetura, Campus de Azurém, Guimarães, Portugal

[b] Technische Universität Berlin, Fakultät VI Planen Bauen Umwelt, Institut für Stadt- und Regionalplanung, Berlin, Deutschland

[c] Universidade Nova de Lisboa, Centro de Humanidades de Ciências Sociais e Humanas, Lisboa, Portugal

Como citar: Mendonça, L. F., \& Mendonça, R. (2021). Culto dos monumentos históricos e projeto imperial na década de 1940: Negociando um passado colonial em Maputo e além. urbe. Revista Brasileira de Gestão Urbana, v.13, e20200157. https://doi.org/10.1590/2175-3369.013.e20200157

\section{Resumo}

\begin{abstract}
A história nacional, do período colonial, celebrada nos memoriais da cidade de Lourenço Marques (renomeada Maputo em 1976), recaía nos triunfos da Ocupação e dos seus heróis, no esforço de Guerra, nos feitos extraordinários, elementos comuns à maioria das histórias nacionais e aos vários projetos imperiais das potências europeias ao longo do século XX. 0 que foi nessa altura símbolo das conquistas do país colonizador tornou-se uma herança problemática na véspera da Independência. A ressemantização do espaço público e a omissão de muito desse espólio, que abrange edifícios, pedaços de cidade e vivências urbanas, tornaram evidente a transferência de poder e um novo projeto político-cultural que procurava contrastar heranças do colonialismo. 0 texto descreve sucintamente a construção de memoriais e a eleição dos monumentos (da colonização) em Moçambique durante a primeira década do Estado Novo português (1933-1974), de forma a refletir sobre a interpretação e validação contemporâneas desse patrimônio em Moçambique. A pesquisa desenrolada em 2014 e 2019 sobre estudos urbanísticos, projetos de restauro de monumentos e legislação do patrimônio de Moçambique das primeiras décadas do século XX, permite estabelecer paralelismos com outras experiências coloniais e, de forma mais significativa, com a discussão atual sobre a conservação de patrimônios "dissonantes".
\end{abstract}

Palavras-chave: Moçambique. Estado Novo. Eleição do património. Restauro dos monumentos.

\footnotetext{
LFM é arquiteta, investigadora de pós-doutoramento, doutora em Arquitetura e Urbanismo e em História e Restauro de Arquitetura, e-mail: lisandramendonca@gmail.com

RM é escultor, doutor em Ciências da Arte, e-mail: rjr.mendonca@gmail.com
} 


\section{Abstract}

The national history commemorated in Maputo's memorials, during the colonial period, comprises the triumphs of the Occupation and its heroes, the War effort, and extraordinary achievements, common elements of most national histories and of the various imperial projects of the European powers throughout the 20th century. What was then a symbol of the colonizing country's conquests became a problematic legacy on the eve of Independence. The ressemantization of public space and the denial of much of this heritage, which includes buildings, cities (built to European standards) and urban experiences, made evident the transfer of power and a new political and cultural project that sought to counter the legacies of colonialism. The text briefly describes the construction of memorials and the selection of monuments in Mozambique during the first decade of Estado Novo (1933-1974), in order to reflect on the contemporary interpretation and validation of heritage in Mozambique. The research carried out in 2014 and 2019, on urban studies, restoration projects of monuments and legislation for heritage in Mozambique from the first decades of the 20th century, allows the establishment of parallels with other colonial experiences and, more significantly, with the current discussion on the conservation of "dissonant" heritages.

Keywords: Mozambique. Estado Novo. Selection of heritage. Restoration of monuments.

\section{Introdução}

0 título deste texto faz referência à obra de Alois Riegl (1858-1905), Der moderne Denkmalkultus: sein Wesen und seine Entstehung (O culto moderno dos monumentos: O seu caráter e a sua gênese) (orig. 1903), de introdução teórica ao projeto de reorganização legislativa da tutela dos monumentos austríaca, marcando uma posição na afirmação da autonomia e relevância histórica paritária de todos os períodos históricos e géneros artísticos. A tutela do patrimônio aparece aqui como um evento temporal determinado, isto é, assente em avaliações de caráter relativo, só temporalmente e contextualmente válidas (Riegl, 2011, p. 14; Scarrocchia, 2011, p. 82 ss.). É a partir deste pressuposto que assenta a discussão que se segue em torno da construção discursiva e material do patrimônio em Moçambique sob o Estado Novo português (1933-1974) e além.

No dia 25 de setembro de 2019, feriado nacional em Moçambique que comemora o início da Guerra de Libertação (1964-1974), fui com o Dr. Moises Tembe (curador da fortaleza de Maputo) a um antigo armazém do Ministério da Educação e Cultura, localizado na Av. das Forças Populares de Libertação de Moçambique (FPLM), em Maputo, à procura de estátuas erigidas pela Administração colonial na cidade. Entre setembro de 1974 e junho de 1975, a maioria desses memoriais foi removida dos locais públicos, com o acordo tácito do Governo de Transição (1974-1975). Em Lourenço Marques (renomeada Maputo em 1976), muitas peças foram depositadas nos terrenos do Museu Nacional de Arte (Figura 1) e algumas foram depois transferidas para um armazém, discutindo-se contemporaneamente o seu destino ${ }^{1}$. No armazém (Figura 2), encontrámos as estátuas de Gago Coutinho, retirada do aeroporto (anteriormente denominado Gago Coutinho); a do Cardeal de Lourenço Marques, D. Teodósio Clemente Gouveia, do Largo dos Heróis da Fé, na Malhangalene, e aquela alegórica da "Colónia de Moçambique" 2 do monumento a Mouzinho de Albuquerque, inaugurado na homônima praça (atual da Independência) em 1940, no quadragésimo quinto aniversário do "feito de Chaimite"3. Escusado será dizer que nenhum dos funcionários que encontrámos no

\footnotetext{
${ }^{1}$ Entrevista realizada pela autora a Alda Costa (chefe do Departamento de Museus, da Direção Nacional do Património Cultural, entre 1986 e 2001), 17 de setembro de 2019. Nos anos seguintes, o Serviço Nacional de Museus e Antiguidades (SNMA) identificou várias estátuas, entre aquelas removidas pelo país, para o novo programa expositivo da fortaleza de Maputo referente à História da Ocupação Colonial e da Resistência, então em discussão. Dificuldades várias travaram o desenrolar desse projeto.

2 Veja-se Portugal... (1940, p. 92 ss.).

3 O Estado Nguni de Gaza dominou uma parte substancial do território que forma atualmente Moçambique até ao final do século XIX (Lemos, 1987, p. 10 ss.; Newitt, 2012, p. 240, p. 334-340). 0 soberano de Gaza, Gungunhana (ca. 18591906), foi aprisionado por Mouzinho de Albuquerque, em 28 de dezembro de 1895, na aldeia fortificada de Chaimite.
} 
armazém (agora afeto a uma empresa de distribuição) conhecia estas peças ou a sua proveniência. 0 desconhecimento relativamente a toponímia, memoriais comemorativos e vivências urbanas correlacionadas do período colonial, estende-se à grande maioria dos habitantes da cidade (ou de passagem) que fui interpelando ao longo da pesquisa, do Alto Maé, à Polana e na Baixa antiga, ou mesmo nos arquivos locais. Ainda que o rasto de muitas peças se considere perdido, algumas foram repostas (e.g. Vasco da Gama e Luís de Camões, na Ilha de Moçambique) ou transferidas para a parada da fortaleza de Maputo - nomeadamente, a do antigo comissário régio António Ennes, por Teixeira Lopes, inaugurada na Baixa de Lourenço Marques em 1910; a do celebrado capitão de cavalaria das campanhas de "pacificação" militar do território da década de 1890, Mouzinho de Albuquerque, por Simões de Almeida (sobrinho), e dois baixos-relevos em bronze, representando trechos das supramencionadas campanhas, por Leopoldo de Almeida, parte do, já referido, monumento a Mouzinho.

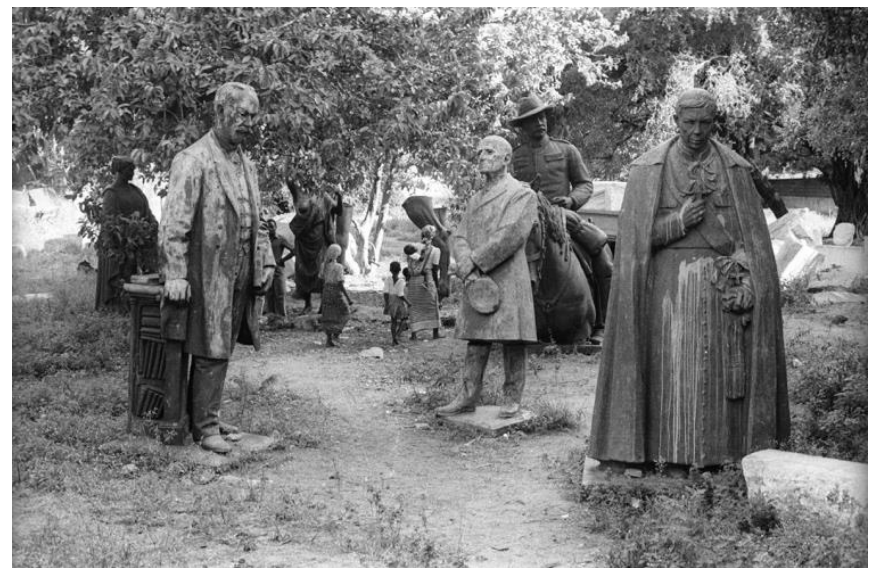

Figura 1 - Estátuas do período colonial, Maputo, 1981. Em primeiro plano, D. Teodósio Clemente Gouveia; à esquerda, António Ennes; ao centro, Gago Coutinho e, logo atrás, Mouzinho de Albuquerque a cavalo. Ao fundo, à esquerda, a "Colónia de Moçambique". Fonte: Rangel (1981).

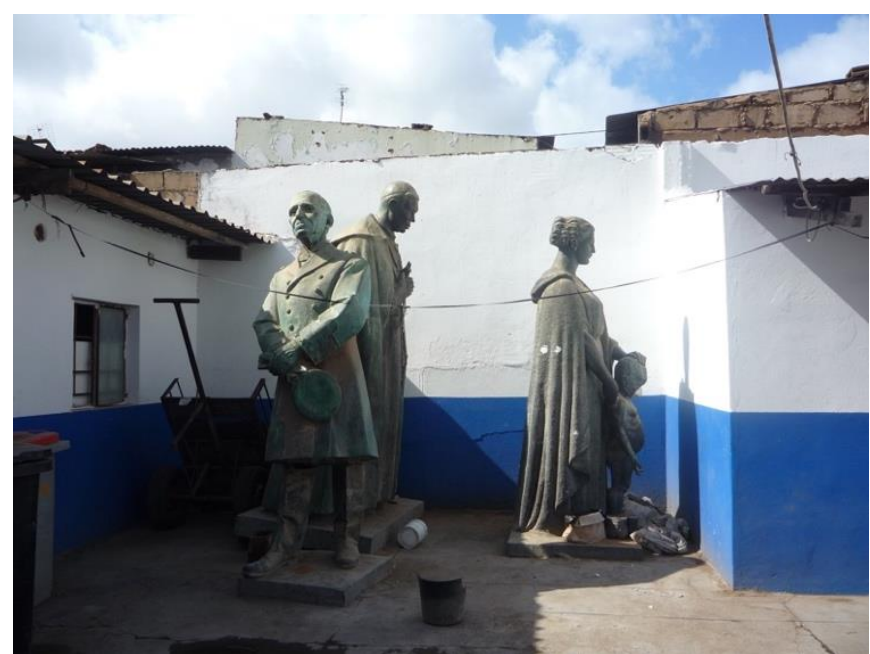

Figura 2 - Estátuas do período colonial: Gago Coutinho, D. Teodósio Clemente Gouveia e a "Colónia de Moçambique", Maputo, 2019. Fonte: Autora.

O confronto das coleções fotográficas do Centro de Documentação e Formação Fotográfica (CDFF) e do Arquivo Histórico de Moçambique (AHM), ambos em Maputo, com as notícias nos periódicos locais, permite entrever como a remoção de estátuas e outros elementos escultóricos identificativos (e, sucessivamente, a alteração de toponímia), permitiu uma imediata ressemantização do espaço público e a visualização da 
transferência de poder. Durante o "7 de Setembro"4, o magazine Tempo refere o "desaparecimento" da estátua de António Salazar do átrio do Liceu Salazar (atual Josina Machel)5. A 8 de novembro, no Notícias, a remoção dos baixos-relevos do plinto de Mouzinho de Albuquerque ${ }^{6}$ (Figura 3), seguindo-se, entre outros, as estátuas de Ennes ${ }^{7}$ e de Mouzinho ${ }^{8}$, bustos, brasões, esferas armilares e cruzes (da Ordem de Cristo) de espaços e edifícios públicos. Em maio de 1975, o Notícias lança um inquérito sobre este tema, publicado no arco de uma semana (com ca. 20 entrevistas a pessoas de diversas origens e estratos sociais). Praticamente todos os entrevistados são unânimes em defender a remoção das estátuas e a sua preservação num museu, reconhecendo que "apenas quando a hora da serenidade histórica" chegasse, poderia haver o distanciamento histórico-crítico necessário para estudar e avaliar a importância dessas "obras de arte e documentos" (Inquérito [a Alexandre Lobato], 1975). Um entrevistado, porém - o historiador Alexandre Lobato - argumentava que os memoriais a "grandes figuras e feitos da História da Humanidade", como os de Vasco da Gama, do Infante D. Henrique, ou da Grande Guerra, deveriam ser mantidos, visto que, "assim como os portugueses [tinham] obrigação de compreender que a hora que passa[va] [era] a da conclusão coerente e lógica dum processo histórico", também o povo de Moçambique devia "saber, [...], que o seu passado [era] ininteligível sem Portugal" (Inquérito [a Alexandre Lobato], 1975). As, já referidas, estátuas de Vasco da Gama e de Luís de Camões da Ilha de Moçambique foram repostas; o Padrão da Grande Guerra, da autoria do escultor Rui Roque Gameiro e do arquiteto Veloso Reis Caramelo, de 1935 (Praça Mac-Mahon/ dos Trabalhadores), e o memorial a Vasco da Gama (portal neomanuelino junto ao Jardim Vasco da Gama/ Tunduru), de 1929, ambos na Baixa de Lourenço Marques, foram mantidos, já os padrões do V Centenário da Morte do Infante D. Henrique foram derrubados.

Tomando as palavras de Bellisari (2017, p. 626), ao analisar o pedido de repatriação feito pelo Estado Argelino de obras de arte francesas transferidas para França nas vésperas da independência, cabe perguntar qual o significado de se considerar algumas obras de arte, de alguns dos mais importantes estatuários da metrópole - Leopoldo de Almeida, Simões de Almeida (sobrinho), Teixeira Lopes, etc. — figurando alguns dos mais celebrados mentores da empresa colonial, propriedade cultural de uma ex-colônia? 0 que está em jogo quando um estado recém-independente considera esse espólio uma "parte valiosa da [sua] herança cultural" (Bellisari, 2017, p. 626; trad. pela autora) ou, por outro lado, o condena à omissão, a damnatio memoriae? Estas questões põem em causa a percepção sobre as lutas pelo patrimônio e a identidade no pósindependência como essencialmente focadas na "retórica anticolonial de libertação nacional - com ênfase na descolonização da mente" (Bellisari, 2017, p. 627; trad. pela autora) -, que pressupõe um conflito entre a valorização e a redefinição da cultura nacional e a do antigo colonizador. Na verdade, o programa da Cultura em Moçambique, no imediato pós-independência, centrou-se nos produtos adequados à Revolução em curso e em contrastar a herança cultural imposta pelo colonialismo. Nesse sentido, todo o aparelho estatal referente à Educação e Cultura foi reformulado e lançada uma campanha de inventário do patrimônio (entre 1978 e 1982), a Campanha Nacional de Preservação e Valorização Cultural (CNPVC) (Costa, 2013, p. 247-249, p. 261 ss., p. 276; Hedges, 1999, p. 222-232). 0 patrimônio edificado produzido pelo colonialismo foi também objeto de levantamento, considerado uma memória da "tenacidade e determinação do [...] [povo de Moçambique]" face à "humilhação e dominação estrangeira", ou seja, como "fonte de inspiração e ensino para as gerações vindouras" (Moçambique, 1979).

\footnotetext{
${ }^{4} \mathrm{Na}$ véspera e até meados da semana seguinte à assinatura dos Acordos de Lusaka, que estabeleceu as condições para a Independência (25 de junho de 1975), Lourenço Marques viveu episódios de violência, contando dezenas de mortos, feridos e detidos (Três dias de desespero..., 1974).

${ }^{5}$ Factos \& Fotos (1974). A estátua de bronze, por Francisco Franco, de 1964, substituiu outra de pedra dinamitada em 1961 por um grupo extremista (Acciaiuoli, 1998, p. 39-73; Portugal... 1952, p. 148; Verheij, 2011, p. 100 ss.). Figurado nas vestes imponentes de Professor Catedrático da Universidade de Coimbra, permanece encostada a uma parede e virada de costas para quem passa, junto ao edifício-sede da Biblioteca Nacional, em Maputo.

${ }^{6}$ Removidos painéis... (1974).

7 Monumentos Removidos... (1975).

8 Portal Arquivo RTP (1975).
} 
A definição de legislação para a proteção do património (substanciando a proteção de todas as suas categorias) - Lei n. 10, de 22 de dezembro de 1988 -, levou em consideração o trabalho nesse sector da Comissão dos Monumentos e Relíquias Históricas de Moçambique (doravante Comissão dos Monumentos), estabelecida em 1943 e vigente até ao final do período colonial; e tomou como referências, entre outras, a reflexão feita no âmbito da CNPVC sobre a História e a Cultura nacionais e o processo de salvaguarda e inscrição da Ilha de Moçambique na Lista do Património Mundial da UNESCO (Naroromele \& Marrengula, 1988, p. 11). A nova lei classificou todos os edifícios erigidos em data anterior a 1920 e os centros históricos das principais cidades (Moçambique, 1988). Considerar que, nos alvores da Independência, decisores políticos moçambicanos defendessem a proteção de patrimônio do período colonial, ilustra uma realidade da remodelação cultural pós-independência mais matizada do que a maioria dos relatos parece sugerir.

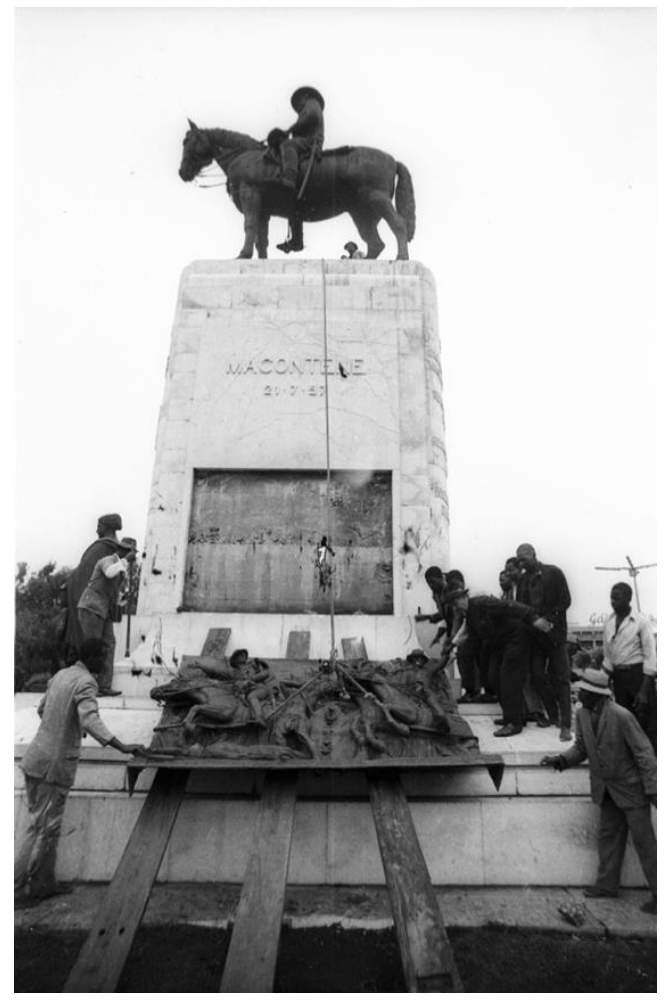

Figura 3 - Remoção dos painéis do pedestal de Mouzinho de Albuquerque (em primeiro plano, o da carga de cavalaria do segundo combate de Macontene [1897]), Lourenço Marques/ Maputo, 1974. Fonte: Rangel (1975).

A história nacional celebrada nos memoriais de Lourenço Marques (e na restante colônia) recaía nos triunfos da Ocupação e dos seus heróis, no esforço de Guerra, nos feitos extraordinários, elementos comuns à maioria das histórias nacionais (Macdonald, 2009, p. 2). 0 que foi nessa altura símbolo das conquistas do país colonizador, tornou-se uma herança problemática na véspera da Independência, impedimento para a "independência total" requerida pelos libertadores, à semelhança do que aconteceu ao longo do século XX noutros contextos de descolonização em África, nas antigas repúblicas soviéticas com a queda da União das Repúblicas Socialistas Soviéticas, ou, já noutro contexto, de recente, a algumas figuras controversas do passado colonial, em algumas praças europeias (e.g. estátua do rei Leopoldo II, em Antuérpia), na sequência do protesto de milhares de pessoas contra o racismo, consubstanciado em atos de vandalismo contra estátuas representativas, segundo os manifestantes, da apologia da violência contra sujeitos racializados.

A construção do património é um fenómeno histórico, assemblado tanto discursivamente como materialmente com a participação e negociação entre vários atores, valendo-se de diferentes quadros e situações culturais. Esses quadros e situações são, simultaneamente, locais e não locais. Ou seja, envolvem condições e atores locais, mas são negociadas frequentemente com recurso e comparações com outros locais e a ideias e conceitos que foram produzidos exteriormente, e com a consciência de serem julgados por outros (Macdonald, 2009, p. 4). Dada a natureza de afirmação identitária da seleção e construção do 
património, essa concentra-se tipicamente nos triunfos e feitos ou nos sacrifícios envolvidos na lutas e realizações da Nação (Macdonald, 2009, p. 2). O período pós-independência observou esses mesmos parâmetros, celebrando os heróis da Luta de Libertação (Samora Machel [1933-1986], Eduardo Mondlane [1920-1969], os Heróis moçambicanos, etc.) e sítios associados à Luta ou à Resistência contra a Ocupação. Os vestígios materiais e os eventos que não se enquadravam na narrativa atinente à revolução políticocultural foram, de sequência, em parte ignorados ou removidos. 0 silenciamento ou a lacuna de informação sobre o património atinge também edifícios e pode envolver a sua destruição física (Macdonald, 2009, p. 23). Este texto, composto por mais duas partes, descreve sucintamente, na segunda, a eleição dos monumentos em Moçambique na década de 1940 e, na terceira, o entendimento contemporâneo relativo à sua valência. Entende-se levantar questões atuais relativas ao entendimento do património erigido pela Administração colonial, com referência na Baixa da cidade de Maputo. A investigação, desenrolada em arquivos institucionais moçambicanos e portugueses, faz parte de um projeto mais extenso que pretende indagar diferentes entendimentos e práticas do patrimônio urbano no Sul Global e reconfigurações formais e estéticas do patrimônio moderno afetado por processos de descolonização que foram cruciais para a construção da Nação e que continuam a investir a identidade e a memória coletiva (trans)nacional.

A investigação, divulgação e conservação do patrimônio do período colonial tem sido objeto de interesse crescente, muitas vezes propagado por grupos externos ao local. 0 reconhecimento público, embora entrevendo aspetos problemáticos de "heranças dissonantes" como aquelas deixadas pelo colonialismo (e dentre elas, a de uma formalização específica do patrimônio dependente de uma história orientada pelo Ocidente) ${ }^{9}$, que não deve servir para apologia ou legitimação, vê a pertinência desse patrimônio (e.g., da arquitetura e do urbanismo) na produção de conhecimento e na remembrança de memórias dos sítios, que têm efeito profundo na identidade autoconsciente (de cada um) e, que, exprimem claramente a contestação inerente à natureza do próprio patrimônio (Tunbridge \& Ashworth, 1996; Macdonald, 2009). Nas palavras de Dolff-Bonekämper (2002, p. 4),

Los monumentos arquitectónicos y artísticos se ofrecen como medios eficaces para el debate y la negociación justamente porque a pesar de toda su belleza y armonía formal, no son en sí mismos portadores de armonía de efecto pacificador. Por el contrario, esos edificios y artefactos constituyen un medio que contiene y preserva los conflictos de la historia que son los que han dado lugar a su existencia y conformación. Este aspecto también abarca las interpretaciones, los discursos científicos y las demandas políticas que han sido vinculadas con los monumentos históricos a lo largo de cada época. Reconocer esos elementos y resignificarlos en relación con el tratamiento del monumento histórico requiere de la especial aptitud de los conservadores patrimoniales: hay que saber "leer" en los edificios la configuración artística y la superposición de múltiples significados. Por supuesto aquí tampoco existe sólo una única lectura posible.

\section{A eleição dos monumentos históricos de Moçambique na década de 1940: "O culto dos monumentos" da colonização}

Desde finais da década de 1930, várias iniciativas refletem a preocupação crescente do Governo português pela inventariação e apresentação pública dos "monumentos" e "relíquias históricas" (cf. Moçambique, 1943a), que evoluiria nos anos seguintes para formar um dos pilares do impulso patrimonial do Estado Novo. 0 entendimento oficial de que os monumentos e o "desenvolvimento" impostos pela colonização legitimavam historicamente a soberania portuguesa ficou patente na "1. ․ Exposição Colonial Portuguesa", realizada no Porto, em 1934. Nesse certame, os visitantes puderam apreciar reproduções de monumentos como a do Arco dos Vice-Reis de Velha Goa ou o (autêntico) Padrão de Diogo Cão (Galvão, 1934, 1934a). Já a "Exposição Histórica da Ocupação Portuguesa no Século XIX”, realizada em Lisboa, em

${ }^{9}$ Cf. Giblin (2018, p. 2). 
1937, apresentou, entre outras, "uma maquete alegórica do feito de Chaimite" e outra do monumento a Mouzinho de Albuquerque (Roteiro da Exposição Histórica..., 1937, p. 8-9), destinado a Lourenço Marques.

Esse mesmo entendimento tomou forma nas várias exposições coloniais da década de 1930, inauguradas durante as visitas presidenciais. Foi o caso da "Exposição-Feira de Angola", em Luanda, de 1938, onde se pôde observar "a reconstituição da histórica Fortaleza de Muxima" (Exposição-Feira..., 1938, p. 13). Ou, em Moçambique, da "Exposição Histórica, Cultural, Comercial e Agrícola", inaugurada em julho de 1939, na cidade da Beira, onde o pavilhão de honra tomou a forma da desaparecida fortaleza de S. Caetano de Sofala, expondo simbolicamente a sua pedra de armas e um Cristo mutilado (Costa, 1940, p. 214). Nas palavras proferidas no certame pelo Presidente da República, Óscar Carmona, a continuidade temporal e a relação direta entre fomento/ monumentos e "ação civilizacional" ficavam evidentes:

A cidade da Beira, admirável realização da moderna capacidade colonizadora dos portugueses, e as pedras gloriosas da fortaleza de Sofala, articulam o passado com o presente, na unidade magnífica do desenvolvimento histórico de Portugal neste recanto do Império (Portugal..., 1939, p. 60).

Entre o final da década de 1930 e inícios da de 1940, na continuidade temporal entre o passado eleito e o presente contemporâneo, aos velhos monumentos vieram juntar-se toda uma série de novos padrões comemorativos e outros memoriais. Em Lourenço Marques, em 20 de julho de 1939, foi inaugurado o Padrão Comemorativo da Primeira Visita Presidencial ${ }^{10}$ e, em 29 de dezembro de 1940, o monumento a Mouzinho de Albuquerque, celebrado no âmbito das comemorações dos Centenários Nacionais de 1940 (VIII Centenário da Formação de Portugal e IV Centenário da Independência Nacional) (Portugal... 1940, p. 99 ss., p. 107). 0 monumento a Mouzinho, colocado no topo do novo eixo cívico que se desenvolvia desde a vetusta Praça 7 de Março/ 25 de Junho (Figuras 4 e 5), vinha complementar a alegoria, inaugurada com o monumento a António Ennes, aos heróis das principais transformações geopolíticas de Moçambique do final do século XIX. No final de dezembro de 1940, foram também inaugurados monumentos comemorativos em Languene, Chaimite e Macontene (Portugal..., 1940, p. 93-94). Deste modo e tendo em conta os que existiam já em Marracuene, Magul, Coolela e Mapuanguene, ficavam "assinalados todos os locais históricos das campanhas de 1895 e 1897" (Portugal..., 1941, p. 112) associados à narrativa portuguesa contemporânea da "pacificação" do território a Sul do Save. Todo este discurso, assente na retórica das qualidades especiais da colonização portuguesa, foi desenrolado em sintonia com o endurecimento da política colonial em Moçambique, "que culminou com a implantação das culturas forçadas e [...] [o] controle estatal rigoroso sobre toda a força de trabalho [indígena]” (Hedges, 1999, p. 123).

\footnotetext{
${ }^{10}$ Foi demolido em 1989 (Cabral, 1989) para dar lugar ao monumento ao primeiro Presidente da República Popular de Moçambique, Samora Moisés Machel.
} 


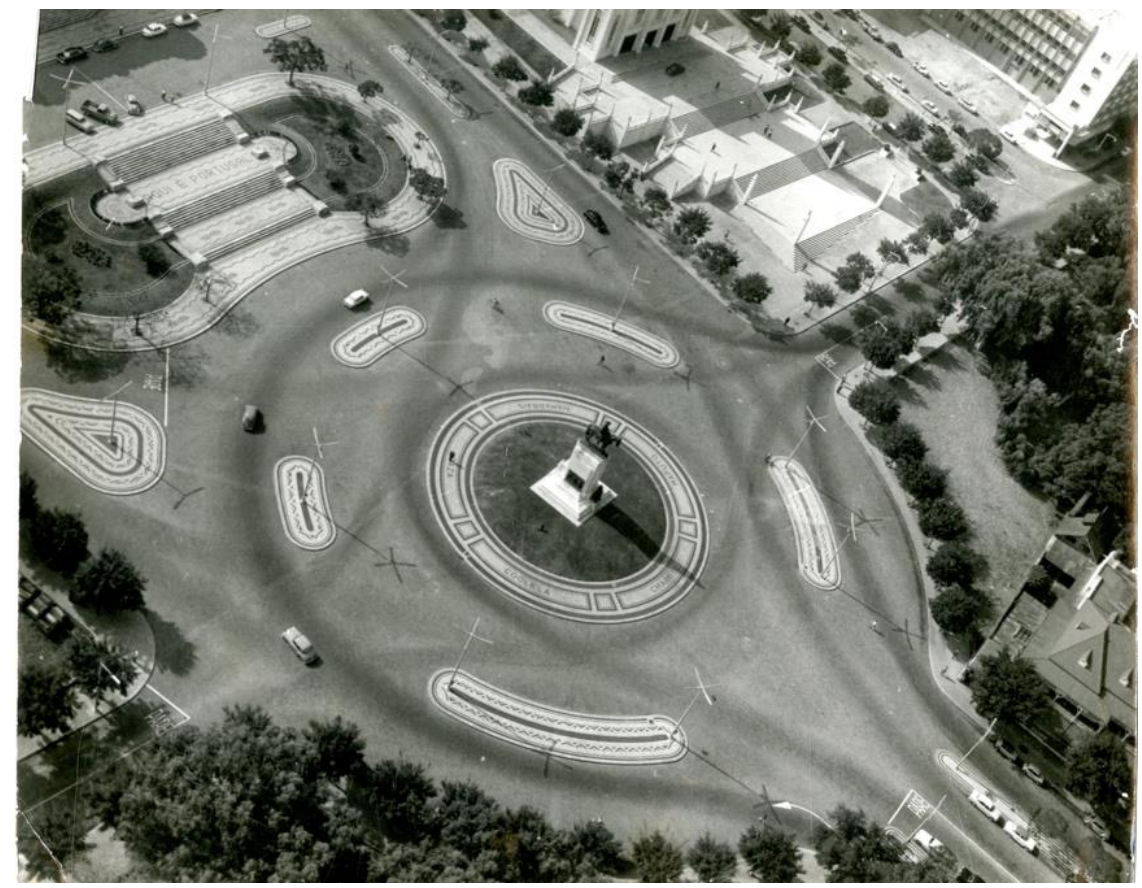

Figura 4 - Vista aérea da Praça Mouzinho de Albuquerque, Lourenço Marques/ Maputo, (n.d.). Fonte: L. M. Vista aérea... (n.d.).

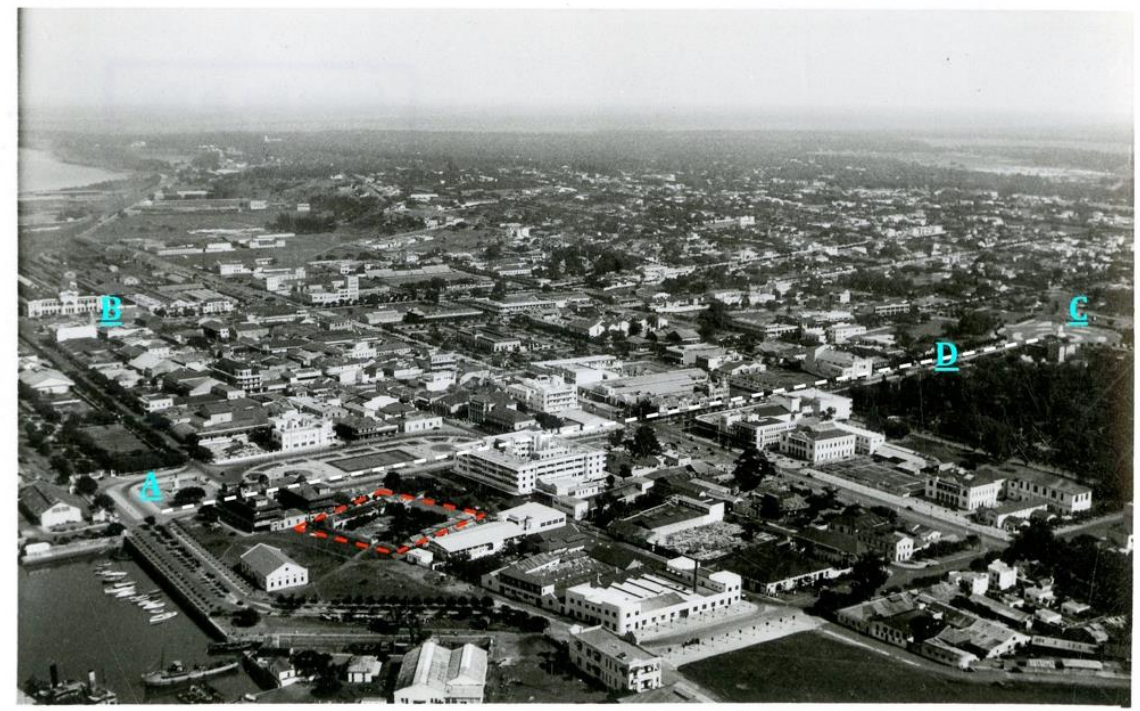

Figura 5 - Vista parcial da cidade de Lourenço Marques/ Maputo, 1943. A: Monumento a António Ennes (Praceta António Ennes [atualmente suprimida]); B: Padrão da Grande Guerra (Praça Mac-Mahon/ dos Trabalhadores); C: Monumento a Mouzinho de Albuquerque (Praça Mouzinho de Albuquerque/ da Independência); D: Padrão da Primeira Visita Presidencial. Entre A e C desenrola-se a antiga Av. Aguiar, sucessivamente D. Luís/ Samora Machel. O retângulo a tracejado assinala a fortaleza de Nossa Senhora da Conceição. Fonte: Adaptado de Pinto (1943).

A necessidade premente de "[...] se garantir a conservação do património arqueológico e histórico da Colónia", que se encontrava em parte já irremediavelmente perdido devido à incúria, desfigurado e humilhado por utilizações impróprias, ou sujeito a desvio para fora da colônia (caso das "antiguidades e relíquias históricas"), levou à constituição da, já referida, Comissão dos Monumentos, à qual competia “[...] investigar, classificar, restaurar e conservar os monumentos e relíquias da Colónia, divulgar o seu conhecimento arqueológico-histórico e promover a sua propaganda cultural e turística" (Moçambique, 1943a).

A propaganda cultural e turística, que associava o monumento ao proveito económico, era uma das razões "práticas" ulteriores expostas por Alexandre Herculano (1810-1877) para a salvaguarda dos 
monumentos: "Um monumento recomendável como objecto de arte é um capital produtivo" (apud Neto, 2001, p. 167). Esse "capital produtivo" começou progressivamente a ganhar forma no discurso oficial na década de 1930 (Neto, 2001, p. 168-170). E, se os monumentos da metrópole faziam, há muito, parte do circuito cultural europeu e eram divulgados nas exposições e feiras internacionais, sobretudo desde o início do Estado Novo (Neto, 2001, p. 167-168), acentuou-se, também, o potencial económico do turismo cultural na propaganda dos territórios ultramarinos (Exposição-Feira..., 1938, p. 12-13, p. 25). Em Moçambique, essa foi devidamente orientada para as colónias vizinhas (África do Sul e "Rodésias"). Ao turismo de lazer — em franco desenvolvimento em Lourenço Marques desde a primeira década de 1900 (Alberto, 1907, p. 179) acrescentou-se o cartaz da cultura, associada aos vestígios e ao caráter ancestral da colonização portuguesa e ao fomento geral do território, formalizado nas infraestruturas de praia, campos de golfe, reservas de caça, rede viária, monumentos e museus.

Encontram-se vários paralelismos entre este entendimento e aqueles atuados noutros contextos coloniais no Norte de África, no início do século XX, na exploração dos monumentos e das "valências" da cultura "indígena" para fins de turismo e ao serviço do "desenvolvimento". O investimento do Governo italiano na promoção do turismo na Líbia incidiu tanto na construção de infraestruturas (rede de estradas e ferroviária, hotéis, etc.), como na preservação dos vestígios arqueológicos do antigo domínio romano (influenciando, desta forma, a percepção sobre a ocupação colonial, numa elaborada relação de dependência entre história e ação civilizacional) (Abbonizio, 2009, p. 49; Fuller, 2007, p. 151-153). Já em Marrocos, a valorização, museumificação e classificação dos monumentos e das cidades pré-coloniais (musealizadas por razões políticas) pela Administração francesa, deveu-se, também, ao seu caráter pitoresco: do ponto de vista recreativo e da exploração comercial/ turística interessava a visão exótica do "outro", aspeto que reentrava na rentabilização dos "recursos" do território (Benjamin, 2003, p. 200-202; Wright, 1997, p. 322-345). Política e cultura aparecem claramente interligadas. Essa condição foi amplamente explorada pelos administradores coloniais e materializada, entre outras, através do planeamento urbano e das suas várias valências: organização funcional, social (e racial), composição arquitetónica e construtiva, definição das tradições e da modernidade.

Em Moçambique, o interesse oficial pela propaganda da legitimidade histórica da ocupação portuguesa colocou o foco da Comissão dos Monumentos nos "monumentos históricos", designação que abrangia construções e sítios arqueológicos do período pré-colonial, "Edifícios significativos da conquista e ocupação do território", associados a factos e "personalidades de relêvo da história da Colónia", e "edifícios oferecendo particular interêsse arquitectónico" (Moçambique, 1943a). De entre esses, e em sintonia com o que decorria na metrópole ${ }^{11}$, foram sobretudo as fortalezas, as igrejas e os palácios erigidos nas áreas geográficas onde primeiro se fez sentir a influência portuguesa (entre os séculos XVI e XVIII, no Norte e Centro do território) que primeiramente foram objeto de inventariação, classificação e restauro. A ideia de monumento aparecia associada, por um lado, aos memoriais, sobretudo estatuária, erigidos "[...] com o objectivo expresso de evocar a memória de acontecimentos e personalidades celebradas pela gesta histórica da nação [portuguesa]" e, por outro, “[...] aparentava remeter para o conceito de monumento histórico, tal como ele foi teorizado por Alois Riegl” (Navarro, 2012, p. 190). Ou seja, como um testemunho material que, de forma alheia à razão da sua criação, é investido de significado particular e celebrado num quadro e tempo históricos precisos pela memória coletiva ${ }^{12}$.

\footnotetext{
${ }^{11}$ Cf. Neto (2001, p. 45).

${ }^{12}$ Riegl descreve os "monumentos intencionais" - criados especificamente para assinalar um evento a recordar pelas gerações sucessivas-, e os "monumentos não intencionais ou involuntários" - que, independentemente das razões que assistiram à sua criação, foram associados sucessivamente a um valor histórico ou artístico, ou, contemporaneamente histórico-artístico, ou seja, cuja "eleição" como monumento histórico e/ ou artístico ficou dependente da vontade subjetiva de quem operou o reconhecimento, isto é, da percepção moderna (Jokilehto, 2006, p. 54).
} 


\section{O restauro de monumentos na cidade de Lourenço Marques}

A cidade de Lourenço Marques, capital e produto recente da reorganização administrativa da colônia ${ }^{13}$, não parecia reter as mesmas condicionantes dos velhos monumentos da antiga colonização e suas "valências" para a Administração portuguesa. Além da classificação pioneira da fortaleza (Moçambique, 1943b), seguida da antiga Residência do Governo (Moçambique, 1964), apenas uma série de poucos edifícios dispersos foram tutelados já na última década do período colonial ${ }^{14}$.

Como conjunto urbano, apenas o da Baixa antiga (Figuras 6 e 7) foi objeto de recomendações especiais no último plano diretor do período colonial (o "Plano Diretor de Urbanização de Lourenço Marques" [PDULM]), aprovado em 197215. O PDULM dava aval, por outro lado, à transformação radical do tecido urbano nas áreas adjacentes, para onde admitia a "Dominância de construções do tipo torre" (Gabinete..., 1969, Vol. XVIII, Peça 63A) (Figura 7). Contemporaneamente, a Comissão dos Monumentos levava adiante algumas campanhas de obras pelo território, constituía museus e procedia ao inventário e ao Tombo do patrimônio, reunindo um espólio considerável sobre obras de arte, sítios, áreas urbanas, o estado de conservação dos monumentos classificados e as obras de restauro operadas, material hoje acessível, em parte, no Fundo do SNMA, no Arquivo do Patrimônio Cultural/ Instituto de investigação Sociocultural (ARPAC), em Maputo (Franco de Mendonça, 2016, p. 244-245).

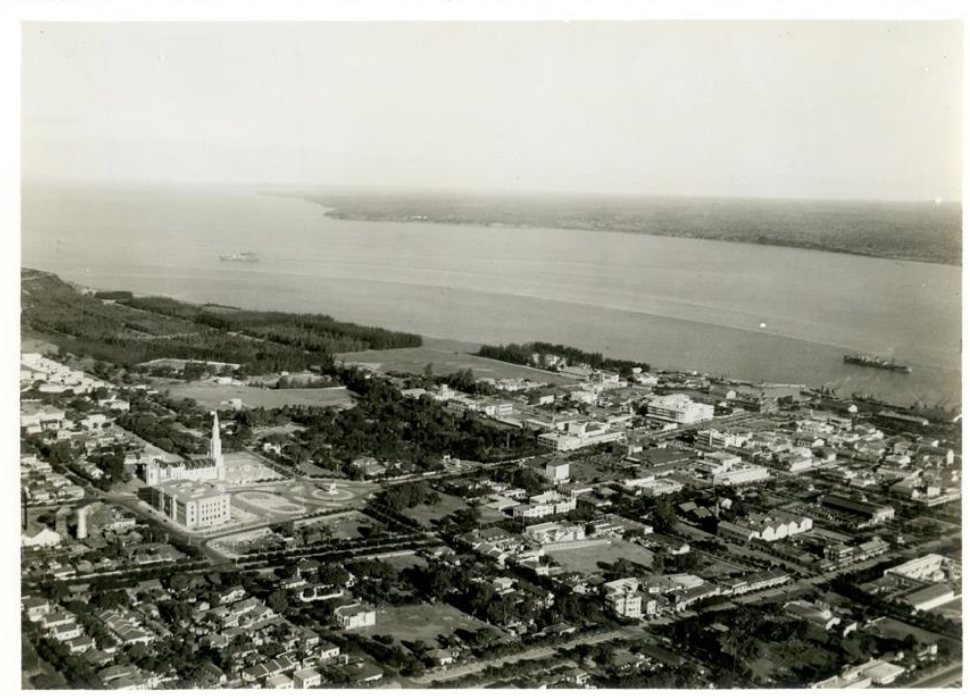

Figura 6 - Vista parcial da cidade de Lourenço Marques/ Maputo, 1946. Na zona ribeirinha, o porto e a Baixa antiga. No sentido oposto, em direção à Alta da cidade, os edifícios da Câmara Municipal e da Catedral ao redor da Praça Mouzinho de Albuquerque. Fonte: [Vista parcial da...] (1946).

No início da década de 1940, o interesse da Administração colonial pelos monumentos da capital recaiu na fortaleza, para a qual referia a necessidade de produzir um plano de urbanização, a integrar no futuro plano da cidade (Portugal..., 1942, p. 144-145). A fortaleza de Nossa Senhora da Conceição, elemento primário e estruturante do núcleo fundacional de Lourenço Marques, entendida contemporaneamente como "[...] o mais antigo testemunho da ocupação e soberania portuguesa na Baía da Lagoa e territórios [...] circunda[ntes]" (Portugal..., 1942, p. 144), foi, de sequência, objeto de um projeto de restauro estilístico, com vista ao seu aproveitamento para museu arqueológico, encomendado ao arquiteto da Direção-Geral dos Edifícios e Monumentos Nacionais (DGEMN), Joaquim Areal da Silva. Porém, o plano de urbanização da cidade que se seguiu (o "Plano Geral de Urbanização de Lourenço Marques", aprovado em 1955) não

13 Cf. Lemos (1987, p. 12).

14 Cf. Franco de Mendonça \& Mendonça (2019, p. 155, nota 12).

15 Cf. Gabinete... (1969, Vol. XXI, Peça 74). 
reconheceu valor à Baixa e, de sequência, não estipulou medidas de salvaguarda para essa área, advogando a sua densificação ${ }^{16}$.

0 projeto de restauro assumiu restituir a fortaleza à configuração de final de setecentos. Convém acentuar que, do edifício primitivo, saqueado e destruído pelos franceses em 1796, não existiam registos anteriores a 1811 que referissem o início da substituição progressiva da primitiva construção em estacaria pela sucessiva em alvenaria de pedra de tufo e cal, que levou décadas a ultimar-se (Lima, 1966, p. 148-149; Silva, 1945, p. 44). Essa construção rudimentar, com um primeiro baluarte concluído na segunda década do século XIX, ameaçou ruína sucessivamente e foi objeto de várias reconstruções faseadas (Lobato, 1970, p. 79-80). A cortina baixa, a sul, arruinada continuamente pela força das águas, foi reconstruída várias vezes. Já nas últimas décadas do século XIX, um projeto da Repartição de Obras Públicas acrescentou-lhe anexos para o aquartelamento e o desenho ornamentado da porta orientada a oeste ${ }^{17}$. 0 aterro do antigo limite ribeirinho, adjacente à Baixa antiga, para a ampliação da estrutura portuária, no início do século XX, alterou definitivamente a relação do edifício com o estuário. Na sequência da demolição faseada de várias construções na envolvente que deita sobre a atual Praça 25 de Junho (anos de 1950-60), também a sua leitura no tecido urbano se alterou significativamente.

Independentemente da análise histórica, dos dados apurados nas sondagens arqueológicas e do estado contemporâneo da construção, a decisão operativa para o restauro conformou-se àquilo que se pretendia do resultado e que pode ser entendido hoje como, nada mais, nada menos, do que a "reconstituição" de um "falso" histórico. Areal da Silva defendia um método para a restituição "do estilo devido" já amplamente testado na metrópole - atinente à purificação linguística, sacrificando estratificações históricasreconhecendo, todavia, alguma limitação prática a esse procedimento (Silva, 1945, p. 35). A mesma, aliás, notada pelos operadores de restauro "estilístico" e "filológico" no final do século precedente, face à dificuldade de criar ex novo partes de monumentos que tinham sido deixadas incompletas ou das quais não possuíam dados fidedignos. Ultrapassavam essa dificuldade, tal como sugeria Areal da Silva, servindo-se da analogia, utilizando outros monumentos, do período histórico eleito, como referência criativa.

Em 1947 decorria a reconstrução da fortaleza, em vias de conclusão em 1951 e em 4 de outubro de 1955 abria ao público na qualidade de Museu Histórico-Militar ([Ficha de inventário da Fortaleza de Nossa Senhora da Conceição], 1982; Portugal..., 1955a, p. 114). O anteprojeto delineado por Areal da Silva foi cumprido praticamente na totalidade (a exceção mais evidente foi a subida da cortina sul para a altura das restantes).

${ }^{16}$ Cf. Portugal (1955b, p. 41-42, p. 102, p. 117-118, p. 173).

${ }^{17}$ Cf. Lobato (1970, p. 89; [não paginado] imagem 56). 


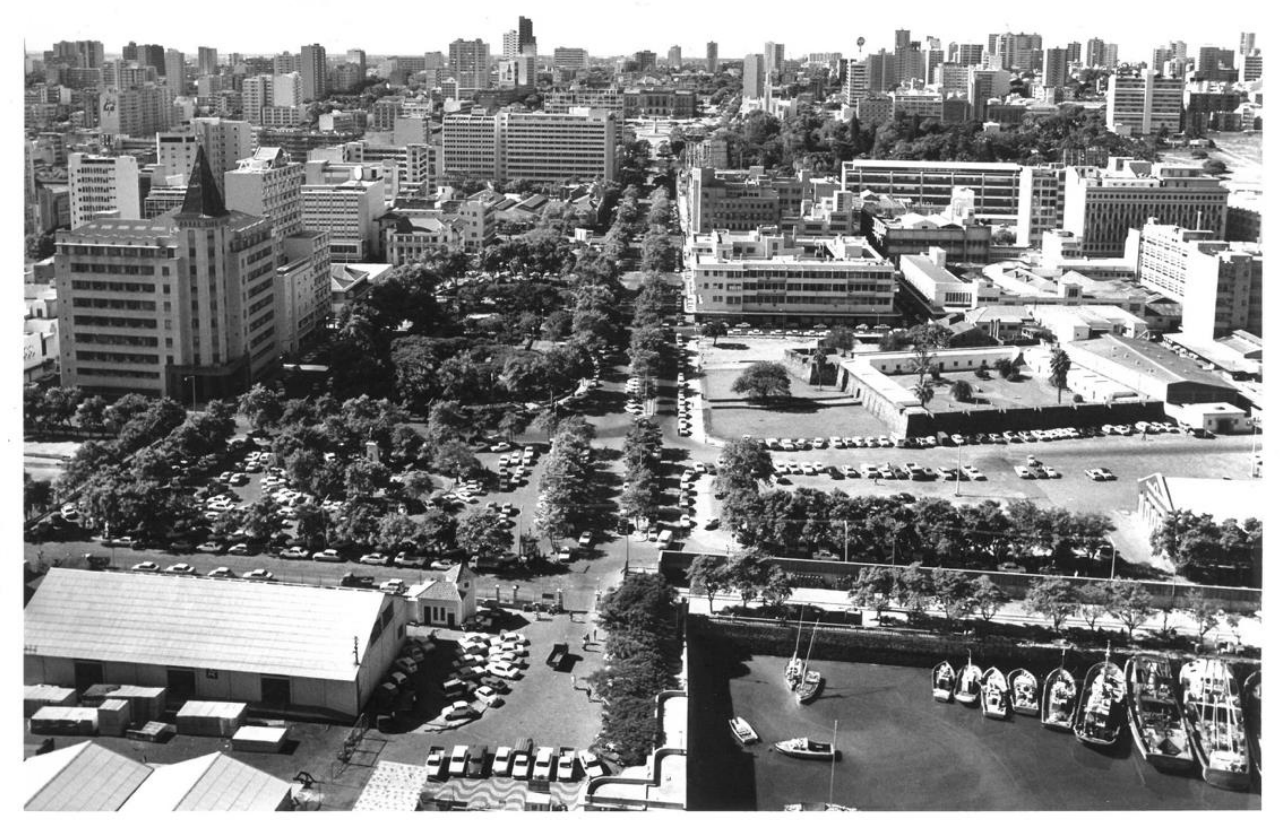

Figura 7 - Vista aérea parcial da Baixa de Lourenço Marques/ Maputo, com a doca da Capitania em primeiro plano, seguida da fortaleza. Ao centro, o grande eixo da Av. D. Luís/ Samora Machel e, à esquerda, a Praceta António Ennes, anexa à Praça 7 de Março/ 25 de Junho, [1974]. Fonte: Lourenço Marques... [1974].

As metodologias de análise histórica e operativa utilizadas no restauro da fortaleza podem ser generalizadas às restantes intervenções levadas a efeito durante a vigência da Comissão dos Monumentos. 0 restauro estava subjacente à restituição do monumento à sua conformação primitiva ou à unidade de estilo "devida". Interessa salientar, para o entendimento do processo de "restituição" da fortaleza na sua temporalidade própria, que os trabalhos desenrolaram-se em consonância com o procedimento e a metodologia corrente de repristinação de monumentos levada a cabo na metrópole pela DGEMN até à década de 1950 e mesmo depois, com resultados amplamente divulgados no âmbito das Comemorações Centenárias ${ }^{18}$ (Franco de Mendonça, 2016, p. 249). Esse processo não deve ser entendido apenas como um procedimento de propaganda cultural e política dos monumentos (da colonização), consonante à condição colonial, mesmo levando em conta que essa condição determinou sobremaneira um entendimento excludente do patrimônio e, de sequência, a sua seleção e divulgação (Franco de Mendonça, 2016, p. 249). O comportamento relativamente ao patrimônio edificado e sua conservação refletia, sobretudo, o próprio (des)entendimento da metrópole e o seu alheamento relativamente à discussão que vinha ocorrendo em torno deste tema em âmbito internacional - e.g., parâmetros de intervenção nos monumentos e nos centros históricos, etc.-, com maior intensidade a partir das primeiras décadas do século XX, mas sobretudo no imediato pós-guerra ${ }^{19}$.

O acesso progressivo a informação (produzida em ambientes externos) por parte dos técnicos dos Serviços de Monumentos e a práticas de intervenção conservativa distintas, através de visitas de estudo e da participação em encontros internacionais, bem como a aproximação entre esses Serviços e os estudos de História da Arte (estudos histórico-artísticos dos monumentos), gerou mudanças lentas no entendimento

18 Cf. Neto (2001, p. 149-151). O interesse do Regime pela divulgação da "valorização" do património e seus inerentes fundamentos teórico-ideológicos ficou patente nos Boletins da Direç̧ão Geral dos Edifícios e Monumentos Nacionais. Para uma série de imagens do "antes" e do "depois" (do restauro) dos monumentos nacionais, associados às grandes campanhas de obras das comemorações centenárias de 1940 e de 1960 (V Centenário da Morte do Infante D. Henrique), veja-se Direcção Geral dos Edifícios e Monumentos Nacionais (DGEMN) (1999).

${ }^{19}$ Sobre essa discussão, veja-se Carbonara (1997, p. 241 ss., p. 285 ss.). 
sobre a validade das diferentes épocas de cada edifício e da sua envolvente urbana, sobre as noções de conjunto e sítio monumental (Neto, 2001, p. 240-241, p. 277, nota 119) e, de sequência, na prática do restauro, na metrópole. Mudanças essas, legitimadas, em parte, pelas sucessivas reestruturações da orientação oficial (Grilo, 1999, p. 5; Neto, 2001, p. 205 ss.). Reconhece-se, no entanto, que no contexto português, o entendimento corrente sobre restauro arquitetónico ficou indefinidamente associado à corrente de reintegrações estilísticas que assolou os monumentos nacionais - especialmente aqueles associados, pela propaganda das primeiras décadas do Estado Novo, à fundação da Nação (1143), à Restauração (de 1640) e ao período áureo dos Descobrimentos (e de sequência ao Império Ultramarino). A análise do comportamento operativo da tutela em Moçambique permite enfatizar que a conservação, valorização e divulgação do patrimônio apareciam subordinadas a uma construção de Identidade que se prendia com o projeto político do Regime. Considerando, nas linhas de Halbwachs (1992) e de Schwartz (1982), o passado sobretudo como uma construção social, moldada tanto pelos interesses do presente, como por um acumular contínuo e episódico de acontecimentos (preservação do passado através de uma continuidade histórica feita com base na seleção) assegurando a continuidade cultural, reconhece-se que a narrativa oficial procurou acentuar o "passado (eleito) e o presente português" da colônia, e um dos pressupostos da "restauração" dos monumentos históricos da colonização: a continuidade entre o tempo passado (pré-determinado) e o tempo contemporâneo ou, por outras palavras, sem que ocorresse a consciência da separação temporal entre o tempo do observador e o tempo da criação da obra do passado. 0 monumento não era, pois, entendido como um evento histórico concluído e celebrado, mas como um tema aberto, pertencente a um "eterno presente" (Sette, 1996, p. 112). A legitimação do poder através da exaltação da continuidade com o passado foi um dos recursos amplamente utilizados pelo Regime: os monumentos, os locais históricos e determinadas figuras da História, foram aproveitados como forma de legitimação política (Harvey, 2001, p. 330-332) ou, como refere Carbonara (1997, p. 52; trad. pela autora), recuperando-lhes determinados aspetos "[...] como sinal de continuidade com o passado e por isso com a autoridade dos antigos".

O "culto dos monumentos" em Moçambique por parte da Administração portuguesa - refiro-me, nomeadamente, às ações de salvaguarda do patrimônio arquitetónico, à musealização dos monumentos, ao desenvolvimento de unidades museológicas, à edificação de memoriais a figuras e acontecimentos da narrativa colonial, etc.- inseria-se num processo e num contexto nacional e internacional precisos. E foram práticas associadas tanto ao processo de "restauração" e fomento do país, como à divulgação da "obra civilizadora" operada e à legitimação da manutenção da soberania portuguesa nos territórios colonizados. Havia que sublinhar, segundo o entendimento contemporâneo, a herança portuguesa, contrariando críticas ao colonialismo que se acentuaram no mundo colonizado com a invasão da Etiópia e o aumento da repressão fascista e que foram ganhando corpo sobretudo no pós-1945 com a criação da Organização das Nações Unidas e o desenvolvimento de processos de descolonização a nível mundial (Hedges, 1999, p. 75-77, p. 198-199).

\section{Conclusões}

Com a instauração do Estado Novo, foi posto em prática um programa político-ideológico de "restauração" e divulgação do património cultural que melhor respondia aos objetivos do Regime. Esse programa passava por inventariar, classificar, restaurar e divulgar edificado com referente na construção de memória do Império Colonial. Uma atitude símile marcou em diversas épocas o "aproveitamento" dos monumentos, por exemplo, o entendimento em grande parte da Europa ao longo do século XIX da mise en valeur do monumento residia no servir um propósito, que (em determinadas situações políticas e nacionalistas) podia criar - reportando o monumento a um modelo - formas emblemáticas (falsas), que facilmente induziam a recordar um antigo esplendor (Ruskin, 1846/ 2007, Introduzione de Stefano, p. 23).

Nas vésperas da Independência de Moçambique, parte desse patrimônio (e.g. certos memoriais comemorativos) foi considerado problemático ou indesejado e, de sequência, removido; parte permanece 
"esquecido" em armazéns ou foi destruído. Foram/são muitas as batalhas pelo patrimônio e a memória na póscolônia (e na pós-metrópole), mas, como argumenta Bellisari, "explorar a história de como uma ex-colônia passou a reivindicar a tutela de [...] obras [...] emblemáticas da cultura do ex-colonizador" (2017, p. 643; trad. pela autora) põe em causa pressupostos e "qualificações totalizantes frequentemente associadas ao drama do desenlace colonial" (p. 644), tido como "ponto final" (p. 644-645). Na verdade, e tal como se esperava, tanto a investigação sobre a eleição, conservação do patrimônio e constituição de um arquivo correlacionado, levadas a cabo pela Comissão dos Monumentos, como a de práticas paralelas no Moçambique pós-independência, mostram os dilemas da construção (discursiva e material) do patrimônio na paisagem urbana, com repercussões que reverberam no espaço e no tempo.

\section{Nota}

A referência a ruas, praças e edifícios da cidade de Lourenço Marques segue a denominação do período colonial, seguida da atual. As transcrições mantêm a grafia de origem. Parte deste artigo foi reescrito, a partir da

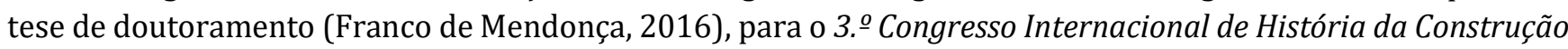
Luso-Brasileira, na Universidade Federal da Bahia, Brasil, em setembro de 2019 (Franco de Mendonça \& Mendonça, 2019).

\section{Referências}

Abbonizio, I. (2009). Musica e colonialismo nell'Italia fascista (1922-1943) (Dissertação de doutorado). Dipartimento di Studi Umanistici, Università degli Studi di Roma "Tor Vergata", Roma. Recuperado em 16 de janeiro de 2021, de https://art.torvergata.it/handle/2108/1196?mode=full\#.XrqH7i1QuRs

Acciaiuoli, M. (1998). Exposições do Estado Novo 1934-1940. Lisboa: Livros Horizonte.

Alberto, C. (1907). Viagem de S. A. o Príncipe D. Luiz Filipe às colónias. O Occidente, XXX (1031), 178-181.

Bellisari, A. (2017). The Art of Decolonization: The battle for Algeria's French Art, 1962-70. Journal of Contemporary History, 52(3), 625-45. 10.1177/0022009416652715

Benjamin, R. (2003). Orientalist aesthetics: Art, colonialism, and French North Africa, 1880-1930. Berkeley/ Los Angeles/ London: University of California Press.

Cabral, J. (1989). [Demolição do Padrão da Visita Presidencial]. (CAB.1 8-D, Cx. Cidade de Maputo 3), CDFF, Maputo, Moçambique.

Carbonara, G. (1997). Avvicinamento al restauro: Teoria, storia, monumenti. Napoli: Liguori Editore.

Costa, A. (2013). Arte em Moçambique: Entre a construção da Nação e o Mundo sem fronteiras (1932-2004). Lisboa: BABEL.

Costa, M. A. da (1940). Do Zambeze ao Paralelo 22ํㅜ : Monografia do território de Manica e Sofala sob a administração da Companhia de Moçambique. Beira: Imprensa da Companhia de Moçambique.

Direcção Geral dos Edifícios e Monumentos Nacionais (DGEMN). (1999). Boletins da DGEMN: Números 1 ao 131. Lisboa: Ministério das Obras Públicas, DGEMN. CD-ROM.

Dolff-Bonekämper, G. (2002). La Cultura Del Patrimonio Entre La Diversidad y La Globalización. Monumentos, 1-5. Recuperado em 16 de janeiro de 2021, de http://www.dolff-bonekaemper.de/monumentos-p.-4.html

Exposição-Feira de Angola. (1938). Guia da Exposição Feira de Angola, Luanda, Agosto 1938. Luanda: [s.n.] (Tip. Agência Técnica de Publicidade).

Factos \& Fotos (9 de junho de 1974). Tempo [Lourenço Marques], (194), 59.

Ficha de inventário da Fortaleza de Nossa Senhora da Conceição. (1982). Serviço Nacional de Museus e Antiguidades (SNMA) (Cx. Maputo-Cidade-Cadastro), ARPAC, Maputo, Moçambique.

Franco de Mendonça, L. (2016). Conservação da arquitetura e do ambiente urbano modernos: A Baixa de Maputo (Dissertação de doutorado). Instituto de Investigação Interdisciplinar, Universidade de Coimbra, Coimbra/ Dipartimento di Storia, 
Disegno e Restauro dell'Architettura, Sapienza Università di Roma, Roma. Recuperado em 16 de janeiro de 2021, de http://hdl.handle.net/10316/29573

Franco de Mendonça, L., \& Mendonça, R. (2019). A Comissão dos Monumentos e Relíquias Históricas de Moçambique (19431975) e o restauro dos monumentos de Lourenço Marques. In Anais do 3. CICLB - 3. Congresso Internacional de História da Construção Luso-Brasileira (p. 153-167). Salvador: Universidade Federal da Bahia, Núcleo de Tecnologia da Preservação e da Restauração.

Fuller, M. (2007). Moderns abroad: Architecture, cities and Italian imperialism. London and New York: Routledge.

Gabinete de Urbanização da Câmara Municipal de Lourenço Marques. (1969). M. de Azevedo (Coord.), Plano director de urbanização de Lourenço Marques (Vol. XVIII, Vol. XXI). Lourenço Marques.

Galvão, H. (1934). Albúm comemorativo da Primeira Exposição Colonial Portuguesa. Porto: Litografia Nacional.

Galvão, H. (1934a). Albúm fotográfico da Primeira Exposição Colonial Portuguesa. Porto: Litografia Nacional.

Giblin, J. (2018). Heritage and the use of the past in East Africa. In Oxford Research Encyclopedia of African History. Oxford, USA: Oxford University Press. https://doi.org/10.1093/acrefore/9780190277734.013.135

Grilo, M. I. T. (1999). Os boletins da Direcção Geral dos Edifícios e Monumentos Nacionais (1935-1990). In Boletins da DGEMN: Números 1 ao 131 (p. 3-7). Lisboa: Ministério das Obras Públicas, DGEMN. CD-ROM.

Halbwachs, M. (com Coser, L. A.). (1992). On collective memory (Heritage of Sociology Series). Chicago/ London: The University of Chicago Press.

Harvey, D. C. (2001). Heritage pasts and heritage presents: Temporality, meaning and the scope of heritage studies. International Journal of Heritage Studies, 7(4), 319- 338. https://doi.org/10.1080/13581650120105534

Hedges, D. (Coord.). 1999. História de Moçambique: Moçambique no auge do colonialismo, 1930-1961 (2a ed., Vol. 2). Maputo: Livraria Universitária, Universidade Eduardo Mondlane.

Inquérito [a Alexandre Lobato]. (7 de maio de 1975). Notícias [Lourenço Marques], 3.

Jokilehto, J. (2006). Alois Riegl e Cesare Brandi nel loro contesto culturale. In M. Andaloro (Ed.), La teoria del restauro del novecento da Riegl a Brandi: Atti del Convegno Internazionale di Studi (Viterbo, 12-15 novembre 2003) (p. 51-57). Firenze: Nardini Editore.

Lemos, M. J. C. (1987). Maputo, deste lado da baía. Considerações sobre a toponímia da cidade. ARQUIVO, Boletim Semestral do Arquivo Histórico de Moçambique, (2), 5-18.

Lima, A. P. de (1966). Edifícios históricos de Lourenço Marques. Lourenço Marques: Livraria e Tipografia Académica.

Lobato, A. (1970). Lourenço Marques, Xilunguíne: Biografia da cidade. Lisboa: Agência-Geral do Ultramar.

Lourenço Marques, Av. D. Luís, atual Av. Samora Machel. [1974]. Coleção do Arquivo da Câmara Municipal de Lourenço Marques (Icon. 4732, Arm. C., Prat. 2, Cx. 56), AHM, Maputo, Moçambique.

L. M. Vista aérea da Praça Mouzinho de Albuquerque, atual Praça da Independência. (n.d.). Coleção do Arquivo da Câmara Municipal de Lourenço Marques (Icon. 4776, Arm. C, Prat. 2, Cx. 6), AHM, Maputo, Moçambique.

Macdonald, S. (2009). Difficult Heritage: Negotiating the Nazi Past in Nuremberg and Beyond. Abingdon, UK: Routledge.

Moçambique (1943a, 20 de fevereiro). Diploma Legislativo n. 825, de 20 de fevereiro de 1943. Cria a Comissão dos Monumentos e Relíquias Históricas de Moçambique. Lourenço Marques: Boletim Oficial da Colónia de Moçambique, I série, n. 8, p. 59-61.

Moçambique (1943b, 3 de abril). Portaria n. 5.093, de 3 de abril de 1943. Proclama monumentos e relíquias históricas da colónia os que são mencionados nesta portaria. Lourenço Marques: Boletim Oficial da Colónia de Moçambique, I série, n. 14, p. 104.

Moçambique (1964, 8 de abril). Portaria n. 17.685, de 8 de abril de 1964. Proclama monumento nacional o edifício da antiga Residência do Governo, propriedade do Estado, situado em Lourenço Marques. Transfere para a Câmara Municipal de Lourenço Marques a propriedade do referido edifício para nele se instalar o Museu da Cidade. Lourenço Marques: Boletim Oficial de Moçambique, I série, n. 14, 478-479. 
Moçambique (1979, 3 de maio). Resolução n. 4, de 3 de maio de 1979. Cria ao nível de cada Assembleia Provincial, uma comissão de inventariação de lugares históricos existentes na província. Maputo: Boletim da República, I série, n. 50.

Moçambique (1988, 22 de dezembro). Lei n. 10, de 22 de dezembro. Estabelece a proteção do Patrimônio Cultural Nacional. Maputo: Boletim [da] República Popular de Moçambique, I série, n. 51, III suplemento, 441-(13) - 441-(17). Recuperado em 16 de janeiro de 2021, de http://www.wipo.int/edocs/lexdocs/laws/pt/mz/mz019pt.pdf

Monumentos Removidos. (15 de maio de 1975). Notícias [Lourenço Marques], 3.

Naroromele, A., \& Marrengula, A. (7 de agosto de 1988). Património Cultural: Lei de protecção em tempo de crise de valores. Domingo [Maputo], 7-11.

Navarro, B. (2012). A estação central de Maputo no contexto das políticas de preservação do patrimônio edificado de Moçambique: Estudo de caso. Historiœ, 3(1), 171-200. Recuperado em 16 de janeiro de 2021, de https://periodicos.furg.br/hist/article/view/3154/0

Neto, M. J. (2001). Memória, propaganda e poder: O restauro dos monumentos nacionais (1929-1960). Porto: FAUP.

Newitt, M. (2012). História de Moçambique. Mem Martins: Publicações Europa-América. (Tradução L. Rodrigues \& M. G. Segurado). (Original publicado 1995).

Pinto, A. te. c. (dezembro de 1943). [Envelope com] Vistas aéreas de Lourenço Marques tiradas pelo t.e. c. Abranches Pinto em dezembro de 1943, Coleção do Arquivo da Câmara Municipal de Lourenço Marques (Icon. 4691, Arm. C, Prat. 2, Cx. 5), AHM, Maputo, Moçambique.

Portal Arquivo RTP. (1975). Derrube da estátua de Mouzinho de Albuquerque [documentário]. Recuperado em 26 de abril de 2020, de https://arquivos.rtp.pt/conteudos/derrube-estatua-de-mouzinho-de-albuquerque/

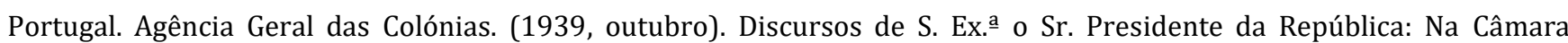
Municipal da Beira em 28 de Julho. Boletim Geral das Colónias, Número especial dedicado à viagem de S. Ex. ${ }^{a}$ o Presidente da República a Cabo Verde, Moçambique e União Sul-Africana, XV(172), 60-63. Recuperado em 16 de janeiro de 2021, de http://memoria-africa.ua.pt/Library/ShowImage.aspx?q=/BGC/BGC-N172\&p=61

Portugal. Colónia de Moçambique (1940, dezembro). Crónica do Trimestre: Glorificação a Mousinho de Albuquerque. Moçambique: Documentário Trimestral, (24), 92-105. Recuperado em 16 de janeiro de 2021, de http://memoriaafrica.ua.pt/Library/ShowImage.aspx?q=/MDT/MDT-N024\&p=93

Portugal. Agência Geral das Colónias. (1941, fevereiro). Homenagem a Mousinho de Albuquerque no 45.ํaniversário de Chaimite. Boletim Geral das Colónias, XVII(188), 104-113. Recuperado em 16 de janeiro de 2021, de http://memoriaafrica.ua.pt/Library/ShowImage.aspx?q=/BGC/BGC-N188\&p=104

Portugal. Colónia de Moçambique (1942, junho). Crónica do Trimestre: Colonização e fomento, monumentos históricos de Moçambique. Moçambique: Documentário Trimestral, (30), 144-145. Recuperado em 16 de janeiro de 2021, de http://memoria-africa.ua.pt/Library/ShowImage.aspx?q=/MDT/MDT-N030\&p=145

Portugal. Colónia de Moçambique (1952, dezembro). Crónica do Trimestre: Liceu Salazar em Lourenço Marques. Moçambique: Documentário Trimestral, (72), 148. Recuperado em 16 de janeiro de 2021, de http://memoriaafrica.ua.pt/Library/ShowImage.aspx?q=/MDT/MDT-N072\&p=149

Portugal. Colónia de Moçambique (1955a, dezembro). Crónica do Trimestre: Museu da Fortaleza de Lourenço Marques. Moçambique: Documentário Trimestral, (84), 114. Recuperado em 16 de janeiro de 2021, de http://memoriaafrica.ua.pt/Library/ShowImage.aspx?q=/MDT/MDT-N084\&p=115

Portugal. Ministério do Ultramar (1955b). Plano geral de urbanização de Lourenço Marques: Peças escritas, memória descritiva e justificativa, regulamento (Vol. 2). Lisboa: Gabinete de Urbanização do Ultramar.

Rangel, R. (1975). Lourenço Marques, 1975 - Momento em que se dava outro destino aos heróis da colónia portuguesa, Coleção Ricardo Rangel (RR01_17_G_04), CDFF, Maputo, Moçambique.

Rangel, R. (1981). [Estátuas nos terrenos do Museu Nacional de Arte], Coleção Ricardo Rangel (RR01_37_E_03), CDFF, Maputo, Moçambique.

Removidos painéis da estátua de Mouzinho. (8 de novembro de 1974). Notícias [Lourenço Marques].

Riegl, A. (2011). Il culto moderno dei monumenti: Il suo carattere e i suoi inizi (S. Scarrocchia, Ed.). Milano: Abscondita. (Original publicado 1903). 
Roteiro da Exposição Histórica da Ocupação Portuguesa no século XIX. (1937). Lisboa: Editorial Ática.

Ruskin, J. (com Stefano, R. Di). (2007). Le sette lampade dell'architettura (6a ed., p. 11-29). Milano: Jaka Book. (Original publicado 1849).

Scarrocchia, S. (2011). La teoria dei valori confliggenti dei monumenti di Alois Riegl. In: A. Riegl, Il culto moderno dei monumenti. Il suo carattere e i suoi inizi (S. Scarrocchia, Ed.) (p. 75-141). Milano: Abscondita.

Schwartz, B. (1982). The social context of commemoration: A study in collective memory. Social Forces, 61(2), 374-397.

Sette, M. P. (1996). Profilo storico. In G. Carbonara (Ed.), Trattato di restauro architettonico (p. 109-299). Torino: UTET.

Silva, J. A. (1945). A Praça de Nossa Senhora da Conceição em Lourenço Marques e o projecto da sua reconstituição. Moçambique: Documentário Trimestral, (43), 23-44. Recuperado em 16 de janeiro de 2021, de http://memoriaafrica.ua.pt/Library/ShowImage.aspx?q=/MDT/MDT-N043\&p=24

Três dias de desespero ou uma lição que temos que aprender. (22 de setembro de 1974). Tempo [Lourenço Marques], (208), 49-54.

Tunbridge, J. E., \& Ashworth, G. J. (1996). Dissonant Heritage: The management of the past as a resource in conflict. Chichester, UK: John Wiley.

Verheij, G. (2011). Monumentalidade e espaço público em Lourenço Marques nas décadas de 1930 e 1940: Dois casos de estudo (Dissertação de mestrado). Faculdade de Ciências Sociais e Humanas (FCSH), Universidade Nova de Lisboa, Lisboa. Recuperado em 16 de janeiro de 2021, de http://hdl.handle.net/10362/7223

[Vista parcial da área da Baixa]. (1946, 30 de maio). Coleção do Arquivo da Câmara Municipal de Lourenço Marques (Icon. 4715, Arm. C, Prat. 2, Cx. 56), AHM, Maputo, Moçambique.

Wright, G. (1991). The politics of design in French colonial urbanism. Chicago: University of Chicago Press.

Editor responsável: Rodrigo Firmino

Recebido: 13 mai. 2020

Aprovado: 19 nov. 2020 